\title{
An Evaluation on Antioxidant Activity, Total Phenolic and Total Flavaonoid Contents of Extracts from Adina cordifolia (Roxb.)
}

\author{
Md. Ali Akbar Hossain 1*, Md. Selim Hossain², Kaniz Fatema1, Benazir Ahmed Siddique1, \\ Hanif Sikder ${ }^{3}$, Md. Sohel Sarker ${ }^{3}$, Preeti Jain ${ }^{1}$ \\ ${ }^{1}$ Department of Pharmaceutical Sciences, North South University, Bashundhara, Dhaka, Bangladesh \\ ${ }^{2}$ Department of Pharmacy, Gono Bishwabidyalay (University), Savar, Dhaka, Bangladesh \\ ${ }^{3}$ Department of Pharmacy, University of Asia Pacific, Dhanmondhi, Dhaka, Bangladesh \\ Email: ${ }^{*}$ akbar bd@yahoo.com
}

Received 2 January 2015; accepted 10 March 2015; published 17 March 2015

Copyright (C) 2015 by authors and Scientific Research Publishing Inc.

This work is licensed under the Creative Commons Attribution International License (CC BY). http://creativecommons.org/licenses/by/4.0/

c) (i) Open Access

\begin{abstract}
In this study, in vitro antioxidant activity, total phenolic content and concentration of flavonoids of four different extracts of Adina cordifolia (Roxb.) were determined using spectrophotometric methods. Antioxidant activity of extracts was expressed as percentage of DPPH radicals' inhibition and $\mathrm{IC}_{50}$ values $(\mu \mathrm{g} / \mathrm{ml})$. IC $\mathrm{I}_{50}$ values ranged from 20.39 to $38.96 \mu \mathrm{g} / \mathrm{ml}$. The total phenolic content ranged from 17.48 to $20.83 \mathrm{mg} / \mathrm{g}$ of dry weight of extract, expressed as gallic acid equivalents. The total flavonoid concentrations varied from 17.49 to $22.48 \mathrm{mg} / \mathrm{g}$, expressed as quercetin equivalents. The significant linear correlation was confirmed between the values for the total phenolic content and antioxidant activity of plant extracts. Adina cordifolia (Roxb.) can be regarded as promising candidates for natural plant sources of antioxidants with high value.
\end{abstract}

\section{Keywords}

Adina cordifolia, Antioxidant Activity, Flavonoids, Total Phenolic Content, DPPH

\section{Introduction}

Nature has provided many things for humankind over the years, including the tools for the first attempt at therapeutic intervention. The World Health Organization (WHO) in its May 2002 report estimated that currently up to $80 \%$ of the African people and a significant percentage of the worldwide population still practice some forms

"Corresponding author.

How to cite this paper: Hossain, Md.A.A., Hossain, Md.S., Fatema, K., Siddique, B.A., Sikder, H., Sarker, Md.S. and Jain, P. (2015) An Evaluation on Antioxidant Activity, Total Phenolic and Total Flavaonoid Contents of Extracts from Adina cordifolia (Roxb.). American Journal of Plant Sciences, 6, 633-639. http://dx.doi.org/10.4236/ajps.2015.65068 
of traditional medical treatment. Typically, these treatments are in the forms of decoctions, tinctures, syrups or ointments with plant or animal products [1]. Many plants species containing active ingredient of medicinal values are yet to be discovered. Folk medicines were the only available treatments until recent times. Drug discovery and development started to follow scientific techniques in the late 1800s.

Oxidizing agents may damage a number of biological molecules, but antioxidant prevents the damage. Many herbs and spices have been reported to exhibit antioxidant activity. Today's researchers are very much interested in antioxidant-based drugs/formulations for the prevention and treatment of various complexes diseases, and the use of natural sources of antioxidant has increased. Natural resources have been reported to main sources of medicinal plant which are used as antioxidant [2]-[9].

The available synthetic antioxidants like butylated hydroxyl anisole (BHA), butylated hydroxy toluene (BHT), tertiary butylated hydroquinone and gallic acid esters have been suspected to cause negative health effects. Hence, there was a trend to substitute them with naturally occurring antioxidants. Furthermore, these synthetic antioxidants also show low solubility and moderate antioxidant activity. Current research is now directed towards finding naturally occurring antioxidants particularly of plant origin [10].

Adina cordifolia (Roxb.) (see Figure 1) (Haldina cordifolia (Roxb.)) belonging to the family Rubiaceae is a large deciduous tree, and grows wild in the hilly region of Bangladesh. Plant parts of Adina cordifolia (Roxb.) are used traditionally in Bangladesh, India, Ceylon, Thailand, and Burma.

It is used by traditional healers for the treatment of chronic cough, and uses in jaundice, stomachache, fodder and swelling in stomach. The roots are astringent and constipating, and are useful in diarrhea and dysentery. The bark is acrid, bitter, astringent, refrigerant, vulnerary, diuretic, demulcent, aphrodisiac and tonic. It is useful in vitiated conditions of pitta, wounds and ulcers, strangury, skin disease, gastropathy, fever and burning sensation. In the literature Adina cordifolia was described having a wide range of medicinal applications. It has been used as antiamoebic, antiinflammatory, antinociceptive and antifertility [11]. Four compounds isolated from the stem of Adina cordifolia were identified as stigmasta-5,22-diene-3P-O-a-rhamnopyranosyl-(1-4)-P-Dxylopyranoside, a-amyrin, octacosanol, and naringenin-7-methyl ether-4'-O-a-rhamnopyranoside on the basis of spectral and chemical evidence [12] [13].

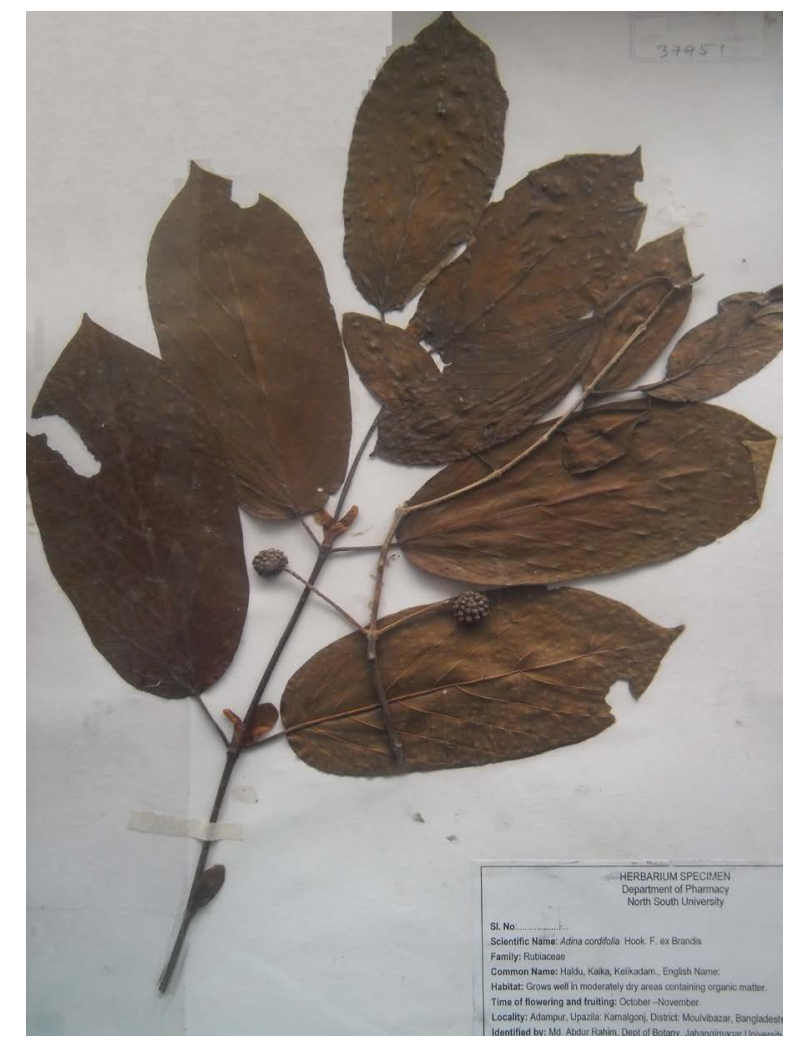

Figure 1. Dried plant of Adina cordifolia (Roxb.). 
The current study was thus designed to provide scientific evidence to the ethno-botanical uses of the plant as antioxidant. So far, this is the first attempt to investigate the antioxidant activity of Adina cordifolia (Roxb.).

\section{Materials and Methods}

\subsection{Plant Material and Extraction Process}

Stem \& bark of Adina cordifolia (Roxb.) was collected from Adampur, Moulavibazar, Bangladesh in April, 2012 and identified by the expert of the National Herbarium, Mirpur, Dhaka, Bangladesh. Accession number DACB-37,951 (see Figure 1) is retained there for further references and the specimen has been preserved in the Phytochemistry and Pharmacology Laboratory, North-South University Bangladesh. The dried powder of stem and bark (250 g) was extracted with n-hexane, ethyl acetate, 95\% of ethanol and subsequently $70 \%$ methanolin room temperature $\left(25^{\circ} \mathrm{C} \pm 2^{\circ} \mathrm{C}\right)$. The extract was concentrated by evaporation under reduced pressure at $40^{\circ} \mathrm{C}$ using rotary evaporator (Bibby RE-200, Sterilin Ltd., UK) to have gummy concentrate of dark green color extract.

\subsection{Phytochemical Analysis}

The freshly prepared crude extract was qualitatively tested for the identification of chemical constituents, such as, alkaloids, flavonoids, steroids, glycosides, saponins, terpenoids, gums and tannins. The tests were carried out by the method described previously and $10 \%(\mathrm{w} / \mathrm{v})$ solution of the extract was taken in each test unless otherwise mentioned in individual test.

\subsection{Evaluation of Antioxidant Activity by DPPH Free Radical Scavenging Assay}

The ability of the plant extract to scavenge DPPH free radicals was assessed by the standard method [14] adopted with suitable modifications [15]. The stock solution of extracts were prepared in methanol or DMSO (nhexane or ethyl acetate extracts) to achieve the concentration of $15 \mathrm{mg} / \mathrm{ml}$. Dilutions were made to obtain concentrations of 500, 250, 125, 62.5, $31.25 \mu \mathrm{g} / \mathrm{ml}$. Diluted solutions (100 $\mu$ leach) were mixed with $3 \mathrm{ml}$ of methanolic solution of DPPH in concentration of $0.002 \%$. Similarly, the stock solution of standard (ascorbic acid) were prepared in methanol to achieve the concentration of $1.5 \mathrm{mg} / \mathrm{ml}$ and dilutions were made to obtain concentrations of 50, 25, 12.5, 6.25, $3.125 \mu \mathrm{g} / \mathrm{ml}$. After $30 \mathrm{~min}$ incubation in darkness at room temperature, the absorbance was recorded at $517 \mathrm{~nm}$. Control sample contained all the reagents except the extract. Percentage inhibition was calculated using Equation (1), whilst $\mathrm{IC}_{50}$ values were estimated from the \% inhibition versus concentration plot, using a non-linear regression algorithm. The data were presented as mean values \pm standard deviation $(\mathrm{n}=3)$.

$$
\% \text { Inhibition }=\left(1-\frac{\text { Absorbanceofsample }}{\text { Absorbanceofcontrol }}\right) \times 100
$$

\subsection{Determination of Total Phenolic Content}

The total phenolic content (TPC) is determined by using the Folin-Ciocalteau method. Absorbance was measured at $765 \mathrm{~nm}$. The content of total phenolic compounds in the plant extract (four types: n-hexane, ethyl acetate, ethanol, methanol extract) of Adina cordifolia (Roxb.) was determined by the method described by Chun et al. (2003) [16].

$0.3 \mathrm{ml}$ of plant extract or standard was taken of different concentration solution in a test tube. $1.5 \mathrm{ml}$ of Folinciocalteu reagent solution was added into the test tube. Then $1.2 \mathrm{ml}$ of sodium carbonate solution was added into test tube. Then the test tubes of standard and extracts solution were incubated for the 30 minutes at room temperature to complete the reaction. Then the absorbances of the solutions were measured at $765 \mathrm{~nm}$ using a spectrophotometer against blank. TPC was expressed as mg gallic acid equivalents (GAE) per gram of sample (mg/g).

\subsection{Determination of Total Flavonoid Content}

The total flavonoid contents were measured by a colorimetric assay [17] [18]. $0.3 \mathrm{ml}$ of plant extract or standard 
was taken of different concentration solution in a test tube. $900 \mu \mathrm{l}$ methanol was added into the test tube. Then $60 \mu \mathrm{l} \mathrm{M} \mathrm{K-acetate,} 1.68 \mathrm{ml}$ distilled water were added into test tube. $60 \mu \mathrm{l} 10 \%$ aluminium chlorides were added to it. Then the test tubes of standard and extract solution were incubated for the 30 minutes at room temperature to complete the reaction. The absorbance of the solutions was measured at $415 \mathrm{~nm}$ using a spectrophotometer against blank. Total flavonoid content of the extracts was expressed as mg quercetin equivalents (QE) per gram of sample (mg/g).

\subsection{Statistical Analysis}

All data are presented as means \pm SD for at least three replications for each prepared sample. Linear regression to correlate between total phenolics as well as total flavonoid with antioxidant activity was carried using Excel 2007.

\section{Results and Discussions}

\subsection{Phytochemical Analysis}

Preliminary phytochemical screening of the plant extract of Adina cordifolia (Roxb.) with different solvents revealed the presence of various bioactive components of which flavonoids, alkaloids, terpenoids, tannins, gums and carbohydrates were the most prominent by observing the color. The result of phytochemical tests has been summarized in the Table 1.

\subsection{DPPH Free Radical Scavenging Assay}

The antioxidant reacts with stable free radical, DPPH and converts it to 1,1-diphenyl-2-picryl hydrazine. The ability to scavenge the free radical, DPPH was measured at an absorbance of $517 \mathrm{~nm}$. So the DPPH and its \% inhibition of n-hexane, ethyl acetate, ethanol and methanolic extract showed that $\mathrm{IC}_{50}$ values $31.36 \pm 0.048$ $\mu \mathrm{g} / \mathrm{ml}, 22.49 \pm 0.023 \mu \mathrm{g} / \mathrm{ml}, 38.96 \pm 0.076$ and $20.39 \pm 0.054 \mu \mathrm{g} / \mathrm{ml}$ respectively. Ascorbic acid has taken as reference which showed $3.125 \pm 0.052 \mu \mathrm{g} / \mathrm{ml}$. Among these results ethyl acetate and ethanol extracts have more potent than other extracts. The overall results of \% inhibition as shown in the (Table 2) respective to $\mathrm{IC}_{50}$ values.

Data set of $n=3 \& \pm$ means Standard Deviation (SD).

Table 1. Phytochemical analysis of the extract of Adina cordifolia (Roxb.).

\begin{tabular}{|c|c|c|c|c|c|c|}
\hline Extract & Tannin & Flavonoid & Saponin & Gum & Alkaloid & Terpenoid \\
\hline NEAC & - & + & - & ++ & +++ & +++ \\
\hline EAAC & - & + & - & ++ & ++ & +++ \\
\hline EEAC & ++ & +++ & +++ & +++ & +++ & +++ \\
\hline MEAC & ++ & ++ & ++ & ++ & ++ & +++ \\
\hline
\end{tabular}

Symbol (+++) indicates presence in high concentration, symbol $(++)$ indicates presence in moderate concentration, symbol $(+)$ indicates presence in trace concentration and symbol $(-)$ indicates absence of the respective phytochemical. NEAC = N-hexane extract Adina cordifolia (Roxb.), EAAC = Ethyl acetate extract Adina cordifolia (Roxb.), EEAC = Ethanol extract Adina cordifolia (Roxb.), MEAC = Methanol extract Adina cordifolia (Roxb.).

Table 2. $\mathrm{IC}_{50}$ value of some extracts and standard ascorbic acid by DPPH assay.

\begin{tabular}{ccc}
\hline Results & Samples & $\mathbf{I C}_{\mathbf{5 0}}$ values $(\boldsymbol{\mu g} / \mathbf{m l})$ \\
\hline & Ascorbic acid & $3.125 \pm 0.098$ \\
\% Inhibition by DPPH & N-hexane & $31.36 \pm 0.078$ \\
& Ethyl acetate & $22.49 \pm 0.071$ \\
& Ethanol & $38.96 \pm 0.079$ \\
\hline
\end{tabular}




\subsection{Determination of Total Phenolic Content}

Phenolics or polyphenols are secondary plant metabolites that are ubiquitously present in plants and plant products. Many of the phenolics have been shown to contain high levels of antioxidant activities [19]. Phenolic compounds contribute to the overall antioxidant activities of plants mainly due to their redox properties. Generally, the mechanisms of phenolic compounds for antioxidant activity are neutralizing lipid free radicals and preventing decomposition of hydroperoxides into free radicals [20] [21].

TPC of extracts was determined by Folin-Ciocalteau (F-C) assay using Gallic acid as a standard phenolic compound (see Figure 2). The F-C assay for total phenolics contents is a fast and simple method and can be useful in characterizing and standardizing botanical samples. F-C method is based on oxidation of phenolics by a molybdotungstate in F-C reagent to yield a colored product with $\lambda \max 765 \mathrm{~nm}$ [22].

The total phenolic contents in the examined plant extracts using the Folin-Ciocalteu's reagent is expressed in terms of gallic acid equivalent (the standard curve equation: $\mathrm{y}=0.158 \mathrm{x}+0.128, \mathrm{R}^{2}=0.9766$ ). The values obtained for the concentration of total phenols are expressed as mg of GA/g of extract (Table 3).

The total phenolic contents in the examined extracts ranged from 17.48 to $20.83 \mathrm{mg} \mathrm{GA} / \mathrm{g}$. The highest concentration of phenols was measured in ethanol, ethyl acetate extracts. Methanol and n-hexane extracts contains considerably smaller concentration of phenols. The total phenolic contents in plant extracts of the species Adina cordifolia (Roxb.) depends on the type of extract, i.e. the polarity of solvent used in extraction. High solubility of phenols in polar solvents provides high concentration of these compounds in the extracts obtained using polar solvents for the extraction [23] [24].

\subsection{Determination of Flavonoid Concentrations in the Plant Extracts}

The concentration of flavonoids in various plant extracts of the species Adina cordifolia (Roxb.) was determined using spectrophotometric method with aluminum chloride. The content of flavonoidswas expressed in terms of quercetin equivalent (the standard curve equation: $\mathrm{y}=0.118 \mathrm{x}+0.020, \mathrm{r}^{2}=0.993$ ), $\mathrm{mg}$ of QUE/g of extract (Table 4). The concentration of flavonoids in plant extracts from Adina cordifolia (Roxb.) ranged from 17.49 to $22.48 \mathrm{mg} / \mathrm{g}$ n-hexane and ethyl acetate extracts contains the highest flavonoid concentration. The lowest flavonoid concentration was measured in ethanol and methanol extracts.

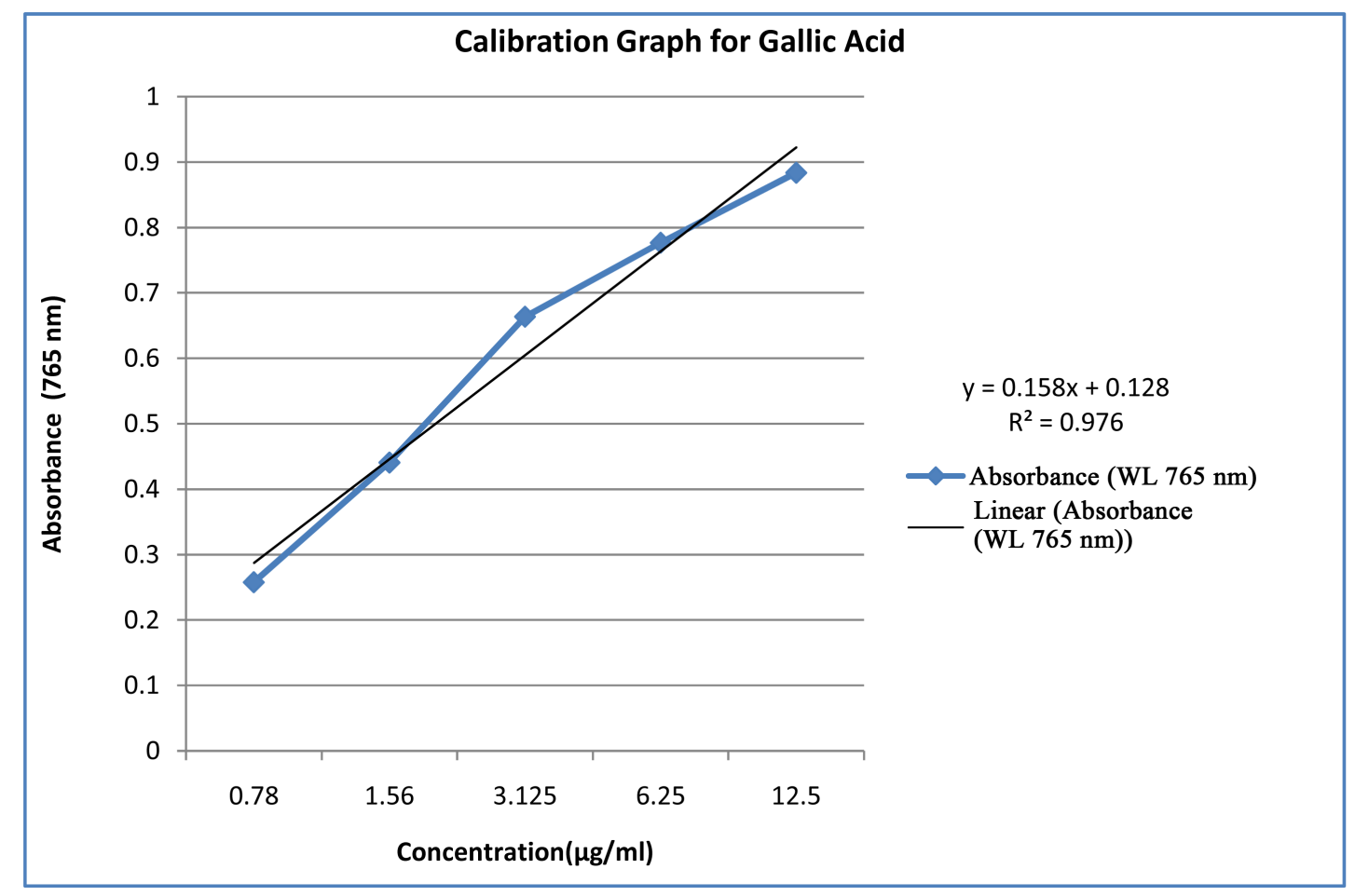

Figure 2. Calibration graph for gallic acid. 
Table 3. Total phenolic contents in the plant extracts expressed in terms of gallic acid equivalent (mg of GAE/g of extract).

\begin{tabular}{cc}
\hline Extract & mg of GAE/g of extract \\
\hline N-hexane & $18.72 \pm 0.612$ \\
Ethyl acetate & $19.98 \pm 0.933$ \\
Ethanol & $20.83 \pm 0.169$ \\
Methanol & $17.48 \pm 0.447$ \\
\hline
\end{tabular}

Table 4. Concentrations of flavonoids in the plant extracts expressed in terms of quercetin equivalent (mg of QUE/g of extract).

\begin{tabular}{cc}
\hline Extract & mg of QUE/g of extract \\
\hline N-hexane & $19.98 \pm 0.259$ \\
Ethyl acetate & $22.48 \pm 0.316$ \\
Ethanol & $18.73 \pm 0.201$ \\
Methanol & $17.49 \pm 0.495$ \\
\hline
\end{tabular}

\section{Conclusion}

In light of the results of the present investigation, we can conclude that the crude extracts of Adina cordifolia (Roxb.) could be a potential source of natural antioxidants that could have great importance as therapeutic agents in preventing or slowing the progress of aging and associated oxidative stress-related degenerative diseases. It also might have an impact to produce antioxidants for food industries as preservatives. However, further studies are needed to understand the underlying mechanisms of antioxidant action and to isolate the compound(s) responsible for such activity.

\section{Acknowledgements}

The authors wish to thank Department of Pharmaceutical Sciences, North South University, Bangladesh for the financial support. The authors also thank all members of the research team.

\section{References}

[1] Ng, R. (2005) Drug Discovery: Small Molecule Drugs. In: Drugs: From Discovery to Approval, Wiley, Hoboken.

[2] Devasagayam, T.P.A., Tilak, J.C. and Boloor, K.K. (2004) Review: Free Radicals and Antioxidants in Human Health: Current Status and Future Prospects. The Journal of the Association of Physicians of India, 52, 794-804.

[3] Deiana, M., Arouma, O.I. and Bianchi, M. (1999) Inhibition of Peroxinitite Dependent DNA Base Modification and Tyrocin Nitration by the Extra Virgin Olive Oil Derived Antioxidant Hydroxytyrosol. Free Radical Biology and Medicine, 26, 762-769. http://dx.doi.org/10.1016/S0891-5849(98)00231-7

[4] Lee, K.G. and Shibamoto, T. (2000) Antioxidant Properties of the Aroma Compounds Isolated from Soyabean and Mung Beans. Journal of Agricultural and Food Chemistry, 48, 4290-4293. http://dx.doi.org/10.1021/jf000442u

[5] Wang, S.Y. and Jiao, H. (2000) Correlation of Antioxidant Capacities to Oxygen Radical Scavenging Enzyme Activities in Blackberry. Journal of Agricultural and Food Chemistry, 48, 5672-5676. http://dx.doi.org/10.1021/jf000765q

[6] Kikuzaki, H., Usuguchi, J. and Nakatani, N. (1991) Constituents of Zingiberaceae I. Diarylheptanoid from the Rhizomes of Ginger (Zin giberofficinale Roscoe). Chemical and Pharmaceutical Bulletin, 39, 120. http://dx.doi.org/10.1248/cpb.39.120

[7] Jitoe, A., Masuda, T. and Tengah, I.G.P. (1992) Antioxidant Activity of Tropical Ginger Extracts and Analysis of the Contained Curcuma Noids. Journal of Agricultural and Food Chemistry, 8, 1337. http://dx.doi.org/10.1021/jf00020a008

[8] Kikuzaki, H. and Nakatani, N. (1993) Antioxidant Effects of Some Ginger Constituents. Journal of Food Science, 58, 1407-1410. http://dx.doi.org/10.1021/jf00020a008

[9] Lee, S.E., Hwang, H.J. and Ha, J.S. (2003) Screening of Medicinal Plant Extracts for Antioxidant Activity. Life Sciences, 73, 167-179. http://dx.doi.org/10.1021/jf00020a008 
[10] Pourmorad, J., Hosseinmehr, S.J. and Shahabimadj, N. (2006) Antioxidant Activity, Phenol and Flavonoid Contents of Some Selected Iranian Medicinal Plants. African Journal of Biotechnology, 11, 1142-1145.

[11] Rokade, S. and Pawar, S.P. (2013) A Comprehensive Review on Adina cordifolia. International Journal of Pharmaceutical Sciences Review and Research, 18, 13-16.

[12] Shrivastva, S.K. (1981) Constituents of Adina cordifolia. Canadian Journal of Chemistry, 61, 1827-1830.

[13] Jack, R., Emil, L. and Vitcha, L. (1980) Isolation of Cadambine from Adina cordifolia Benth. and Hook. F. Science Asia, 6, 54-58. http://dx.doi.org/10.2306/scienceasia1513-1874.1980.06.054

[14] Tekao, T., Watanabe, N., Yagi, I. and Sakata, K. (1994) A Simple Screening Method for Antioxidant and Isolation of Several Antioxidants Produced by Marine Bacteria from Fish and Shellfish. Bioscience, Biotechnology, and Biochemistry, 58, 1780-1783.

[15] Kumarasamy, Y., Byres, M., Cox, P.J., Jasapars, M., Nahar, L. and Sarker, S.D. (2007) Screening Seeds of Some Scottish Plants for Free-Radical Scavenging Activity. Phytotherapy Research, 21, 615-621. http://dx.doi.org/10.1002/ptr.2129

[16] Chun, O.K., Kim, D.O. and Lee, C.Y. (2003) Superoxide Radical Scavenging Activity of the Major Polyphenols in Fresh Plums. Journal of Agriculture and Food Chemistry, 51, 8067-8072. http://dx.doi.org/10.1021/jf034740d

[17] Jia, Z.S., Tang, M.C. and Wu, J.M. (1999) The Determination of Flavonoid Contents in Mulberry and Their Scavenging Effects on Superoxide Radicals. Food Chemistry, 64, 555-559. http://dx.doi.org/10.1016/S0308-8146(98)00102-2

[18] Zou, Y.P, Lu, Y.H. and Wei, D.Z. (2004) Antioxidant Activity of Flavonoid-Rich Extract of Hypericum perforatum L in Vitro. Journal of Agriculture and Food Chemistry, 52, 5032-5039. http://dx.doi.org/10.1021/jf049571r

[19] Razali, N., Razab, R., Junit, S.M. and Aziz, A.A. (2008) Radical Scavenging and Reducing Properties of Extracts of Cashew Shoots (Anacardium occidentale). Food Chemistry, 111, 38-44. http://dx.doi.org/10.1016/j.foodchem.2008.03.024

[20] Javanmardi, J., Stushnoff, C., Locke, E. and Vivanco, J.M. (2003) Antioxidant Activity and Total Phenolic Content of Iranian Ocimum Accessions. Food Chemistry, 83, 547-550. http://dx.doi.org/10.1016/S0308-8146(03)00151-1

[21] Li, H.Y., Hao, Z.B., Wang, X.L., Huang, L. and Li, J.P. (2009) Antioxidant Activities of Extracts and Fractions from Lysimachia foenum-graecum Hance. Bioresource Technology, 100, 970-974. http://dx.doi.org/10.1016/j.biortech.2008.07.021

[22] Prior, R.L., Wu, X. and Schaich, K. (2005) Standardized Methods for the Determination of Antioxidant Capacity and Phenolics in Foods and Dietary Supplements. Journal of Agriculture and Food Chemistry, 53, 4290-4302.

[23] Mohsen, M.S. and Ammar, S.M.A. (2009) Total Phenolic Contents and Antioxidant Activity of Corn Tassel Extracts. Food Chemistry, 112, 595-598. http://dx.doi.org/10.1016/j.foodchem.2008.06.014

[24] Zhou, K.Z. and Yu, L.L. (2004) Effects of Extraction Solvent on Wheat Bran Antioxidant Activity Estimation. LWTFood Science and Technology, 37, 717-721. 